\title{
Retrieval of Model Grid-Scale Heat Capacity Using Geostationary Satellite Products. Part I: First Case-Study Application
}

\author{
RICHARD T. MCNIDER \\ Department of Atmospheric Science, University of Alabama in Huntsville, Huntsville, Alabama \\ WILLIAM M. LAPENTA \\ NASA Marshall Space Flight Center, Huntsville, Alabama \\ Arastoo P. BiazAR \\ Department of Atmospheric Science, University of Alabama in Huntsville, Huntsville, Alabama \\ Gary J. Jedlovec and Ronnie J. Suggs \\ NASA Marshall Space Flight Center, Huntsville, Alabama \\ JONATHAN PLEIM \\ Atmospheric Science Modeling Division, National Oceanic and Atmospheric Administration/Air Resources Laboratory, Research \\ Triangle Park, North Carolina
}

(Manuscript received 12 August 2004, in final form 22 February 2005)

\begin{abstract}
In weather forecast and general circulation models the behavior of the atmospheric boundary layer, especially the nocturnal boundary layer, can be critically dependent on the magnitude of the effective model grid-scale bulk heat capacity. Yet, this model parameter is uncertain both in its value and in its conceptual meaning for a model grid in heterogeneous conditions. Current methods for estimating the grid-scale heat capacity involve the areal/volume weighting of heat capacity (resistance) of various, often ill-defined, components. This can lead to errors in model performance in certain parameter spaces. Here, a technique is proposed and tested for recovering bulk heat capacity using time tendencies in satellite-retrieved surface skin temperature (SST). The technique builds upon sensitivity studies that show that surface temperature is most sensitive to thermal inertia in the early evening hours. The retrievals are made within the context of a surface energy budget in a regional-scale model [the fifth-generation Pennsylvania State UniversityNational Center for Atmospheric Research Mesoscale Model (MM5)]. The retrieved heat capacities are used in the forecast model, and it is shown that the model predictions of temperature are improved in the nighttime during the forecast periods.
\end{abstract}

\section{Introduction}

The behavior of the nocturnal boundary layer is critical to operational weather forecasts of minimum temperatures and winds related to agricultural freeze warn-

Corresponding author address: Dr. Richard T. McNider, National Space Science and Technology Center, 320 Sparkman Drive, Huntsville, AL 35605.

E-mail: mcnider@nsstc.uah.edu ings, utility load forecasting, transportation fog advisories, and other interests. Additionally, air pollution exposure from surface sources is often highest in stable conditions as a result of a lack of ventilation and vertical mixing. Ironically, long-term exposure of humans and plants to certain air pollutants, such as ozone, can occur when the nocturnal boundary layer fails to stabilize, allowing the continued downward flux of ozone from the residual boundary layer above. The behavior of the atmospheric boundary layer, especially the noc- 
turnal boundary, is critically dependent on the surface heat capacity, or, more generally, a surface resistance parameter.

In the following, a technique for recovering an effective grid-scale heat capacity or resistance parameter using evening skin temperature time tendencies from geostationary satellites is described. The use of the morningtime tendencies of air (Mahfouf 1991) and skin (McNider et al. 1994, hereinafter McN94; Norman et al. 1995) temperatures has been employed to recover information relative to surface moisture. However, the use of evening skin tendencies for retrieving information on the surface heat capacity or resistance has not been reported. The recovery of soil moisture and the recovery of heat capacity, as presented here, have common attributes in that both are based on the model sensitivity studies of Carlson (1986) and Wetzel et al. (1984). These show (for reasonable parameter spaces) that the morning rise in surface temperature is most dependent on surface moisture, whereas the evening tendencies are most sensitive to thermal inertia. In both cases the sensitivity assessment assumes that most of the error in a modeled skin tendency is the result of errors in the specification of the most sensitive variable. Both techniques are similar in that they also assume that other terms in the surface heat balance are correct. This is an assumption that can fail. McN94 used special observations from the First International Satellite Land Surface Climatology Project (ISLSCP) Field Experiment (FIFE) and Mahfouf (1991) from the Hydrological Atmospheric Pilot Experiment-Modélisation du Bilan Hydrique (HAPEX-MOBILHY) to evaluate the other terms in the equations.

Here, initial tests of recovering the heat capacity are presented. While the results of these tests are encouraging in that the use of the recovered heat capacity improved model predictions of the nocturnal boundary layer, the general application of this technique may have to be limited to certain synoptic situations. In a second part of this paper (R. T. McNider et al. 2005, unpublished manuscript, hereinafter Part II), the behavior of the stable boundary layer is explored, and this analysis shows that the recovery of the heat capacity may, in practice, be limited to certain parameter spaces. Additionally, it addresses the day-to-day consistency of the retrieved heat capacities and issues with sensitivity and numerical solution techniques.

\section{Background on the heat capacity parameter}

Before discussing the satellite assimilation strategies, we review surface energy budget formulations and, specifically, the role of surface heat capacity in weather forecast and global climate models. Most early mesoscale models (Mahrer and Pielke 1976; Physick 1976; McNider and Pielke 1981) utilized a heat balance equation at the surface of the following form:

$$
0=R_{N}+H+G+E,
$$

where $R_{N}$ is the net radiation (including net shortwave, incoming atmospheric longwave, and outgoing longwave), $H$ is the sensible heat flux, $G$ is the soil heat flux, and $E$ is the latent heat flux. The surface was represented as an infinitesimally small layer with zero heat capacity. Temperature was calculated through rootfinding techniques, and heat capacity was not relevant in the flux to this infinitesimal surface because heat capacity has no meaning for a zero mass surface and cancels in the definition of the ground heat flux,

$$
G=C_{g} \kappa \partial T_{S} / \partial z=C_{g} \frac{\lambda}{C_{g}} \partial T_{S} / \partial z .
$$

Here, $T_{S}$ is the soil temperature, $C_{g}$ is the soil volumetric heat capacity (soil density times specific heat capacity), $\lambda$ is the soil thermal conductivity, and $\kappa$, which combines heat capacity and conductivity, is referred to as the soil diffusivity (McCumber and Pielke 1981; Peters-Lidard et al. 1998). Note that this equation neglects advection and normally assumes vertical homogeneity in the soil. The heat capacity is relevant to the local change of temperature in the soil

$$
\frac{\partial T_{S}}{\partial t}=\frac{\lambda}{C_{g}} \partial T_{S} / \partial z
$$

potentially impacting $G$ by affecting the surface gradient $\partial T_{S} / \partial_{Z}$. McCumber and Pielke (1981) also considered that the heat capacity and diffusivity should include dependence on soil moisture.

Other early models (Blackadar 1979; Bhumralkar 1975) used a prognostic equation for the surface temperature of the form

$$
C_{b}\left(\frac{\partial T_{G}}{\partial t}\right)=R_{N}+H+G+E,
$$

where $T_{G}$ is the surface temperature. This form now includes what is referred to as a storage term $C_{b} \partial T_{G} / \partial t$, because it represents the imbalance in the forcing terms on the right-hand side. The definition and interpretation of $C_{b}$ depends on what the surface includes. Blackadar (1979) took the surface to be a uniform slab that is representative of bare soil. Thus, $C_{b}$ represented the heat capacity over some assumed depth of the slab, that is, $C_{b}=C_{g} \times d_{S}$. Blackadar also specified $C_{b}$ such that it included the diurnal frequency $\omega$ and conductivity so that the single-layer slab model would replicate 
the phase and amplitude of the surface temperature from that of a multilayer, analytical soil model. Thus, for the slab model, the depth $d_{S}$, as a scaling parameter, enters through the conductivity and thermal forcing frequency so that

$$
C_{b}=\left(\frac{\lambda C_{g}}{2 \omega}\right)^{1 / 2}
$$

Here it can be seen that $C_{b}$ involves both volumetric heat capacity and thermal conductivity, and is sometimes referred to as the heat capacity per unit area of the slab, or what we will refer to as bulk heat capacity (Pleim and Xiu 1995). This is the basic form of the force-restore model that is implemented in the fifthgeneration Pennsylvania State University-National Center for Atmospheric Research Mesoscale Model (MM5), described by Grell at al. (1994).

In a similar context of an analytical model, Carlson et al. (1981) defined the thermal inertia $\chi$,

$$
\chi=\left(\lambda C_{g}\right)^{1 / 2},
$$

as a key parameter in the response of the surface to energy inputs. Other investigators, such as Wetzel and Chang (1988), examining fluxes over vegetative canopies, considered that the surface might include vegetation or standing water, such as dew. They suggested that $C_{b}$ represented a vegetation-layer capacity that is determined as the biomass fraction times the heat capacity of water plus the dew. Thus,

$$
C_{b}=\left(b_{m}+W_{R}\right) C_{W},
$$

where $b_{m}$ is the water-equivalent biomass fraction, $W_{R}$ is the water or dew on the vegetation, and $C_{W}$ is the heat capacity of water (Argentini et al. 1992).

Smirnova et al. (1997) provided an interfacespanning formulation that included both the soil and a thin atmospheric layer. Then,

$$
C_{b}=\left(\rho_{A} c_{P} \Delta z_{A}+C_{g} \Delta z_{s}\right),
$$

where $\rho_{A}$ is the air density, $\Delta z_{A}$ is the thin atmospheric layer depth, and $\Delta z_{s}$ is the first layer soil depth.

As investigators begin to apply the equations in models where both bare soil and vegetation might be present (Noilhan and Planton 1989; Jacquemin and Noilhan 1990), the form of the equations was changed to write the heat capacity as a heat capacity coefficient $C_{T}$, the inverse of the heat capacity parameter $C_{b}$, that is,

$$
\left(\frac{\partial T_{G}}{\partial t}\right)=C_{T}\left(R_{N}+H+G+E\right) .
$$

The heat capacity coefficient was then usually determined as a harmonic average of the heat capacities of vegetation, soil, or other substances. For example, Noilhan and Planton (1989) used

$$
C_{T}=1 /\left(\frac{1-\mathrm{veg}}{\tilde{C}_{b g}}+\frac{\mathrm{veg}}{\tilde{C}_{b v}}\right) .
$$

Here, $\tilde{C}_{b g}$ represents the heat capacity coefficient for soil, and $\tilde{C}_{b v}$ represents the vegetation coefficient. ${ }^{1}$ Because the importance of the inclusion of soil moisture freezing has been established (Viterbo et al. 1999; Boone et al. 2000), more complicated forms have been used, such as

$$
C_{T}=1 /\left[\frac{(1-\mathrm{veg})(1-f)}{\tilde{C}_{b g}}+\frac{(1-\mathrm{veg}) f}{\tilde{C}_{b i}}+\frac{\mathrm{veg}}{\tilde{C}_{b v}}\right],
$$

by Giard and Bazile (2000), where $f$ is the fraction of frozen water in the soil and $\tilde{C}_{b i}$ is the heat capacity coefficient of ice.

The correct specification of the vegetative capacity has been subject to debate as well as, perhaps, the specification of $C_{T}$ in general. Pleim and Xiu (1995) argued that the value for vegetative heat capacity that was used by Noilhan and Planton (1989) $\left(\tilde{C}_{b v}=10^{-3} \mathrm{~K}\right.$ $\mathrm{m}^{2} \mathrm{~J}^{-1}$ ) was far too large for reasonable model performance. This was also indicated by Manzi and Planton (1994). Mahfouf et al. (1995) proposed $\tilde{C}_{b v}=2 \times 10^{-5}$ $\mathrm{K} \mathrm{m}^{2} \mathrm{~J}^{-1}$. Giard and Bazile (2000) reduced this value even further to $\tilde{C}_{b v}=8 \times 10^{-6} \mathrm{~K} \mathrm{~m}^{2} \mathrm{~J}^{-1}$. (One has to be careful when discussing large and small, reduce or increase, because $\tilde{C}_{b}$ is the inverse of $C_{b}$.)

In fact, there has been substantial tuning of the $C_{T}$ parameter based on model performance, with arguments for the tuning based on uncertainties in vegetative canopy heat transfer. Even for bare soils the effects of moisture and texture on heat capacity makes specification difficult. For complex settings, such as mixed land uses that are encountered in general weather forecasts and in GCMs, the specification of $C_{b}$ or $C_{T}$ is far from being settled. In the following we will use the term bulk heat capacity to refer to this parameter, but intend that its meaning is that of a combined heat capacity and heat transfer parameter, as given in Eqs. (10) or (11).

In examining Eqs. (1) or (6), it seems clear that because $C_{b}$ or $C_{T}$ is a direct multiplier of all of the flux

\footnotetext{
${ }^{1}$ Here trying to put the notation across the literature in a common form is difficult. We use $\sim$ to indicate that the $\tilde{C}_{b}$ is $1 / C_{b}$ so that $\tilde{C}_{b}$ has units of inverse joules times meters squared times kelvins, which is the inverse of the units of the heat capacity parameter $C_{b}$ in Eq. (2) above.
} 
terms, its magnitude should be critical to model the ground temperature performance. Errors or uncertainty in the specification of $C_{T}$ of factors up to orders of magnitude, as discussed above, are of considerable concern in getting the right surface tendency and, ultimately, the right surface temperature in NWP models and GCMs. The error in specifying $C_{T}$ is at least as large as errors in the actual flux terms. One only has to imagine the real-world example of the eastern United States, which has mixed vegetation of different types, different soils and textures, rocks, roads, standing water, and so on, to recognize the difficulty in specifying $C_{B}$ for a model grid. The following discusses a proposed technique for specifying the heat capacity/resistance parameter using satellite data as an observational constraint. Fundamentally, the technique uses the satellite radiometer to measure the surface temperature change over the model grid area to derive an improved effective bulk heat capacity parameter. This is somewhat equivalent to the way in which a laboratory uses a thermometer to measure temperature change for a known input of energy to determine a heat capacity of some substance. In the present application, the "known" energy input is not perfect because these are the flux terms, but sensitivity analyses bolster the confidence that more error may exist in the a priori specification of $C_{B}$ than in the flux terms. The following outlines the technique.

\section{Methodology}

Carlson et al. (1981) and others have argued that the surface energy terms with the largest uncertainty, in terms of their impact on model sensitivity, are the thermal inertia $\left(\lambda C_{g}\right)^{1 / 2}$, defined above, and the surface moisture availability. Figure 1 from Carlson (1986) shows the sensitivity of a model to variations of the key model parameters. For the range of reasonable specification and uncertainty, the morning temperature is most sensitive to moisture availability, and the evening temperature is most sensitive to thermal inertia. Other factors, such as roughness, and so on, showed less sensitivity for reasonable ranges of specification. For example, moisture availability might truly span the range from near 0.0 to 1.0, but one would not expect the error in roughness specification to span the range from $1 \mathrm{~cm}$ to $5 \mathrm{~m}$. Carlson (1986), Price (1982), and others developed techniques to use day and night passes of polarorbiting IR sensors as two independent pieces of information to simultaneously recover thermal inertia and surface moisture availability. The techniques showed promise in case studies; however, the inversion process did not always produce a unique solution. Further, sta- tionary conditions over the 12 -h passing time of the polar orbiters that were required for the technique were not always met. Thus, while these techniques were pioneering, they have evidently not been widely used in the initialization of operational NWP models or other mesoscale model applications.

To avoid some of the difficulty with the Carlson (1986) and Price (1982) polar-orbiter technique, Wetzel et al. (1984) proposed to use midmorning skin temperature tendencies from geostationary satellites to recover the surface moisture availability. McN94, building upon the work of Carlson, Price, and Wetzel et al., developed a technique to use morning skin temperatures tendencies from Geostationary Operational Environmental Satellite (GOES) to recover soil moisture. Jones et al. (1998a,b) extended the work of McN94 by retrieving stomatal resistance. Lapenta et al. (1999) implemented the technique within the MM5 system (Grell et al. 1994), and the technique has undergone extensive testing in a semi-operational setting for weather forecasts and air pollution modeling applications. It has proved to decrease model bias and standard error of temperature and humidity in long-term statistical tests (Lapenta et al. 1999). Diak and Whipple (1995) have also used morning tendencies for the specification of model parameters to improve model performance.

We now turn our attention to the other term identified by Carlson (1986), in addition to moisture availability, that has large uncertainty, and yet to which the surface cooling rate is sensitive-thermal inertia (and related heat capacity). As noted above, heat capacity is an extremely difficult quantity to specify based on traditional land use data. The following describes the use of an observational constraint-evening skin temperatures from GOES - in a mesoscale model to recover the bulk grid-scale heat capacity.

\section{a. Retrieval of bulk heat capacity using evening skin tendencies}

Following McN94, we first define the surface energy budget of the model for a composite surface (the mixture approach; Koster and Suarez 1992) as

$$
C_{b_{m}}\left(\frac{d T_{G}}{d t}\right)_{m}=\left(R_{N}+H+G\right)_{m}+E_{m}
$$

and the energy budget observed by the satellite as

$$
C_{b_{s}}\left(\frac{d T_{G}}{d t}\right)_{s}=\left(R_{N}+H+G\right)_{s}+E_{s},
$$

where $d T_{G} / d t$ is the rate of change of the land surface temperature (LST), $R_{N}$ is the net radiation (including net shortwave, incoming atmospheric longwave, and 

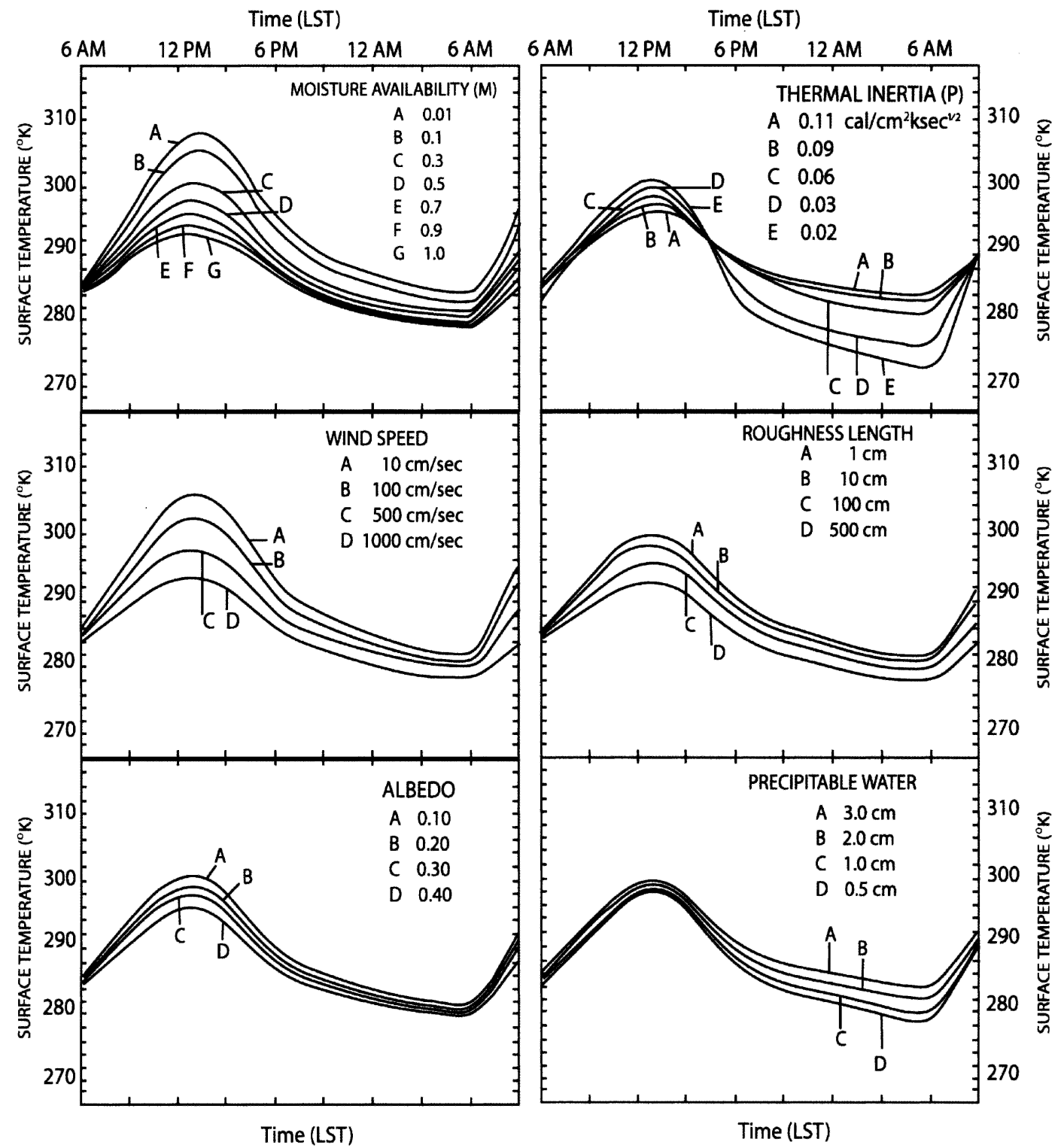

FIG. 1. Sensitivity study adapted from Carlson (1986) showing strong dependence of skin temperature tendencies on moisture availability in the morning and thermal inertia in the evening.

outgoing longwave), $H$ is the sensible heat flux, $G$ is the soil heat flux, and $E$ is the latent heat flux. The subscripts $m$ and $s$ denote the model and satellite variables, respectively. Because we are now considering a composite surface representing the characteristics of vegetation, soil, and so on, rather than bare soil, as discussed above, $C_{b}$ is no longer simply a heat capacity, but is more like a resistance to forcing.

Based on the sensitivity work of Carlson (1986) and Wetzel et al. (1984), McN94 made the critical assumption that all of the terms in the model's surface energy budget are the same as that for the actual energy budget observed by the satellite, except for the latent en- ergy term $E$. With this assumption, we take the difference of Eqs. (12) and (13) to obtain

$$
E_{s}=C_{b}\left[\left(\frac{d T_{G}}{d t}\right)_{s}-\left(\frac{d T_{G}}{d t}\right)_{m}\right]+E_{m}
$$

where $\left(d T_{G} / d t\right)_{s}$ is calculated from hourly GOESderived LST products that are interpolated to the model grid. These GOES-derived LST products are described in section $3 \mathrm{c}$.

The way in which the moisture flux is adjusted within the model is dependent upon the flux formulation. In McN94, the surface specific humidity was analytically 
recovered from similarity theory using this satelliteinferred evapotranspiration $\left(E_{s}\right)$. In MM5, surface specific humidity is not a prognostic variable. Therefore, the moisture availability parameter was retrieved. This is also accomplished through inversion of surface similarity expressions (Lapenta et al. 1999).

Returning to the energy budgets as seen by the model and satellite in Eqs. (8) and (9), respectively, we now consider that the model $C_{b m}$ may be different than the satellite $C_{b s}$. We will also employ the sensitivity results of Carlson (1986) to make the assumption that the evening skin tendencies are most sensitive to thermal inertia (and related heat capacity). Carlson and others have suggested that the balance in the nocturnal boundary layer is dominated by the longwave outgoing radiation from the surface and the flux of heat from the ground flux. This balance is best realized under light winds and for simple bare-soil situations. Under such conditions, or if we make the assumption that moisture availability has been correctly specified (or is negligible, which may be largely true if stomata have closed), we can subtract Eqs. (12) and (13) to solve for $C_{b s}$. We assume that there is negligible difference in net radiation, sensible heat flux, and soil heat flux. Thus,

$$
C_{b s}=C_{b m}\left(\frac{d T_{G}}{d t}\right)_{m} /\left(\frac{d T_{G}}{d t}\right)_{s} .
$$

The assumption made here about the soil heat flux being specified correctly in the model is perhaps incongruous with the arguments above that the heat capacity or thermal inertia are not well known. However, for convenience we make the assumption that all of the error is initially in $C_{b m}$ rather than in both $C_{b m}$ and the soil heat flux. As an alternative, because $C_{g}$ is contained in the soil heat flux term Eq. (2) and in $C_{b m}$, one could attempt to solve for $C_{g}$ directly using both terms, although the inversion would be more difficult. However, for this first attempt we solve for $C_{b s}$ and then change $C_{g}$ using Eq. (3) in the heat flux terms.

The initial value for the model $C_{b m}$ would be determined in the normal fashion from land use information (see below). The new $C_{b s}$ would be subsequently used as the model value; thus, the new $C_{b}$ does impact the ground heat flux. We believe the natural averaging in the satellite IR pixel is an advantage in the technique described below for recovering the composite surface grid-scale $C_{b}$. In carrying out the above retrieval, one has to be especially careful that the satellite is actually seeing the surface to determine the skin temperature tendencies. Cloud masks are more difficult to define in the evening. Section $3 c$ describes the satellite processing and methods for deducing the tendencies that are needed in Eq. (15).
We recognize that the above characterization of the surface energy budget in Eq. (12) is highly simplified, and that $C_{b}$ contains multiple physical factors, such as canopy mechanical and radiative exchange, soil and vegetative heat capacity, and so on. However, given that the actual surface is incredibly complicated and does not lend itself readily to a first-principle model and the associated multiple parameters that would be involved, we believe that $C_{b}$ as a model heuristic constrained by observations has utility in many modeling endeavors.

\section{b. Use and specification of bulk heat capacity in MM5}

In the present study, we employ MM5 to recover the bulk heat capacity and, thus, as a preface give details of how heat capacity and thermal inertia are used and specified in MM5. Based on the Blackadar (1979) approach discussed above [see Eq. (3)], in MM5 $C_{b}$ is related to thermal conductivity $(\lambda)$, heat capacity per unit volume $\left(C_{g}\right)$, and the angular velocity of the earth $(\omega)$ by

$$
\begin{aligned}
C_{b}=0.95\left(\frac{\lambda C_{g}}{2 \omega}\right)^{1 / 2} & =3.293 \times 10^{6}\left(\lambda C_{g}\right)^{1 / 2} \\
& =3.293 \times 10^{6} \chi,
\end{aligned}
$$

where thermal inertia $\left[\chi=\left(\lambda C_{g}\right)^{1 / 2}\right]$ is supplied (cal $\left.\mathrm{cm}^{-2} \mathrm{~K}^{-1} \mathrm{~s}^{-1 / 2}\right){ }^{2}$ Except for the five-layer soil model $C_{b}$ is used for all soil options within MM5. For the five-layer soil model, volumetric heat capacity $\left(C_{g}\right)$ is recovered from thermal inertia and, subsequently, the bulk heat capacity $\left(C_{b}\right)$ is obtained as

$$
C_{b}=C_{g} \times \Delta z
$$

where $\Delta z$ is the top soil-layer thickness $(1 \mathrm{~cm})$. From Eq. (4) thermal inertia $(\chi)$ is related to thermal conductivity $(\lambda)$ and volumetric heat capacity and using the definition of diffusivity in Eq. (2),

$$
\lambda=\kappa C_{g} .
$$

According to Dudhia (1996), $\kappa$ is chosen as a fixed value of $5 \times 10^{-7}\left(\mathrm{~m}^{2} \mathrm{~s}^{-1}\right)$ to represent an intermediate value between sand and clay soil $\left(\kappa=10^{-6}\right.$ for hard rock). Now replacing the above relationship for thermal conductivity in the definition of thermal inertia yields

$$
\chi=\left(\kappa C_{g}^{2}\right)^{1 / 2}=\kappa^{1 / 2} C_{g} .
$$

\footnotetext{
${ }^{2}$ Note that the origin of the 0.95 factor in Eq. (16) is evidently to replicate higher harmonics. The original Blackadar (1979) paper used 1.0.
} 
Therefore,

$$
C_{g}=\kappa^{-1 / 2} \chi=1414.2 \chi .
$$

Including the conversion factor $\left[4.18 \times 10^{4}\left(\mathrm{~J} \mathrm{cal}^{-1}\right) \times\right.$ $\left.\left(\mathrm{cm}^{2} \mathrm{~m}^{-2}\right)\right]$ for MM5, $C_{g}$ is then calculated as

$$
C_{g}=\left(5.9114 \times 10^{7}\right) \chi
$$

In MM5, thermal inertia $(\chi)$ is taken from the land use table (provided as input to the model). For the U.S. Geological Survey (USGS), 24-category land use table, there are only 5 values for thermal inertia $(\chi \times 100)$, ranging from 2 (for bare ground tundra) to 6 (for water). Figure 2 shows the 25 -category vegetation type obtained from the USGS interpolated to a $12-\mathrm{km}$ grid over the southeast using the standard preprocessing package available with the MM5 modeling system. Only 16 of the available 25 types exist in the domain. Evergreen needleleaf is the dominant category stretching east-northeastward from southern Mississippi into the northern half of Georgia. Dry land crop pasture is found along the Mississippi River and southern Georgia, while deciduous broadleaf vegetation and crops/ woods mosaic covers Tennessee.

Figure 3 shows the associated heat capacity as defined from the land use connected thermal inertia in the MM5 terrestrial initialization package. It can be seen that the bulk heat capacity in the model domain has very little spatial variability. In fact, the only variation found over land is associated with urban centers. Such a homogeneous field is clearly not representing the complexities of heat capacity in the real world.

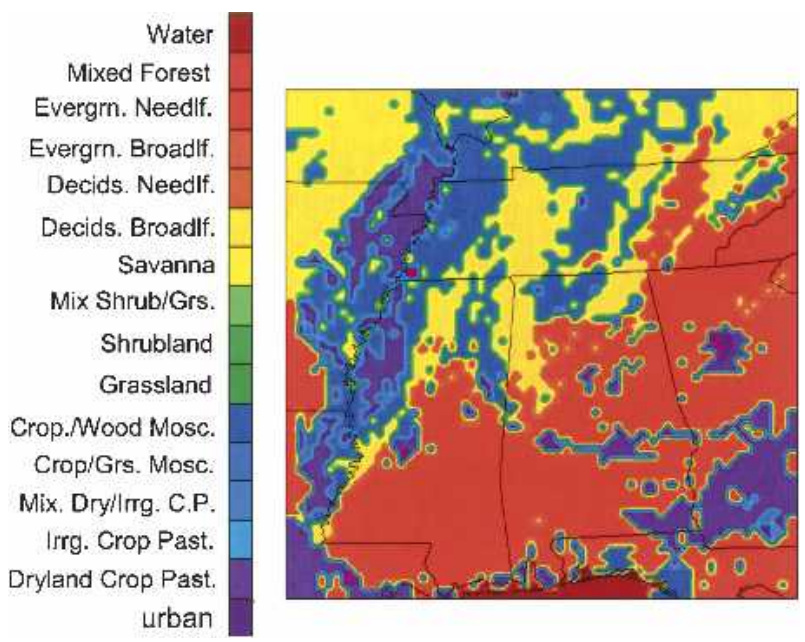

FIG. 2. Land use classification on the 12-km MM5 grid as specified using the 25-category USGS dataset available in the modeling system.

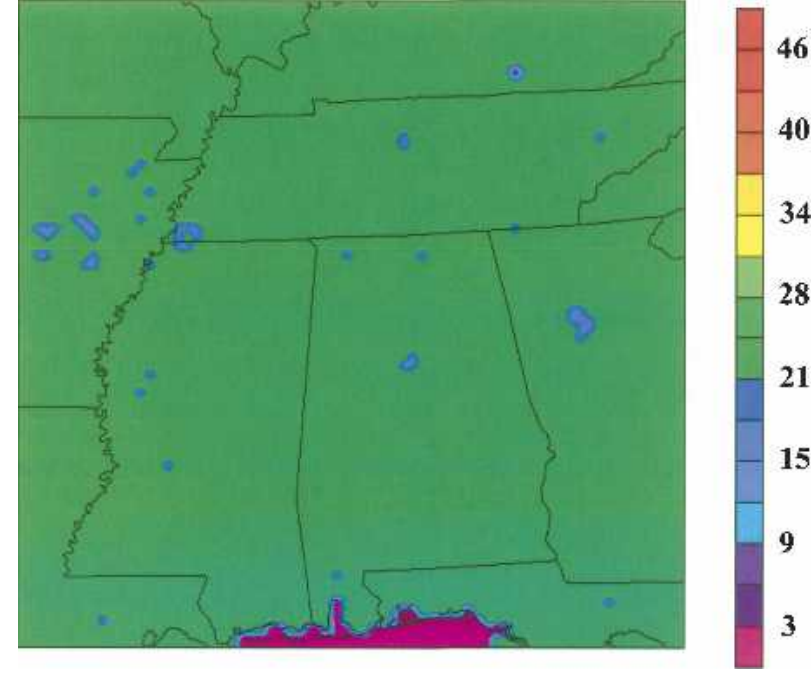

FIG. 3. Default heat capacity $\left(\mathrm{KJ} \mathrm{m}^{-2} \mathrm{~K}^{-1}\right.$ ) obtained using the 25-category land use USGS dataset in the MM5 modeling system.

\section{c. Satellite processing}

The satellite data that are used in this study are from the GOES-8 imager, which is a five-channel (one visible, four infrared) imaging radiometer designed to sense radiant and solar-reflected energy from sampled areas of the earth. The visible channel has $1-\mathrm{km}$ resolution while the shortwave $(3.7 \mu \mathrm{m})$ and thermal infrared window (10.8 and $11.8 \mu \mathrm{m})$ channels have 4-km resolution. Additional details on the GOES I-M series of satellites may be found in Menzel and Purdom (1994).

A critical element in providing useful satellitederived LST retrievals during the early evening and nighttime hours is the ability to consistently monitor and quantitatively detect cloud cover. The clouddetection algorithm used with GOES data requires the 11- $\mu \mathrm{m}$ longwave and the 3.9- $\mu \mathrm{m}$ shortwave images, two 20-day composite images generated from the 11- minus 3.9- $\mu \mathrm{m}$ differences, and an $11-\mu \mathrm{m}$ 20-day maximum temperature composite image. The output from the cloud mask algorithm is a simple pixel resolution image with values indicating either the presence or absence of a cloud. Details of this cloud-detection method for GOES can be found in Jedlovec and Laws (2003).

The procedure for the retrieval of insolation and LST is described in detail by Haines et al. (2004). An abbreviated version is presented below. The insulation retrievals followed Gautier et al. (1980) and Diak and Gautier (1983), using visible radiances corrected for drift in the GOES-8 optical/detector response (Rao et al. 1999). Insulation values derived in cloudy regions include a bulk parameterization of the cloud effects. Hourly insolation estimates were retrieved at each 
model grid point over the domain of interest from an average of 1-km pixel values. LST was retrieved with a physical algorithm developed by Jedlovec (1987) and applied by Guillory et al. (1993) to GOES data. The algorithm inverts a perturbation form of the radiative transfer equation to simultaneously solve for total precipitable water and LST. The algorithm relies on the radiative transfer equation to form a physical (rather than statistical) representation of the atmosphere and uses a priori (guess) thermodynamic data to constrain the retrieval. Retrievals were made using GOES hourly observations that are valid at $45 \mathrm{~min}$ past the hour. GOES imager radiance data from a $3 \times 5$ pixel array centered on each model grid point were checked for clouds averaged to produce a single radiance value for retrieval. A minimum of six clear pixels were required for a retrieval to be made from the gridpoint-averaged radiance. MM5 forecast grids of thermodynamic data (temperature and mixing ratio as a function of pressure) from a model control run were used as input to the transmittance code (McMillin and Fleming 1976) to generate the guess data need for the retrieval algorithm. Garand et al. (2001) have shown that this transmittance formulation produces an adequate representation of brightness temperatures for window channel observations.

It is difficult to quantify the accuracy of GOES LST retrievals. Errors in satellite-derived skin temperature can come from many sources: sensor calibration, instrument noise, algorithm biases, and weaknesses in underlying assumptions (either in the mathematical formulation or in the use of a priori data). Suggs et al. (1998) indicated that for idealized conditions (known surface emissivities, no instrument calibration or random noise errors), LST could be accurately retrieved with this technique to within $0.20 \mathrm{~K}$. No significant diurnal variation in this performance or guess dependence was observed. Most recently Suggs et al. (2003) compared GOES imager LST retrievals to MODIS retrievals produced by Wan and Dozier (1996) [available from the National Aeronautics and Space Administration (NASA) Earth Observing System (EOS) Distributed Active Archive Center (DAAC)]. GOES-8 imager retrievals exhibited an overall 1.2-1.5-K warm bias compared to the Moderate Resolution Imaging Spectroradiometer (MODIS) skin temperature values over the southeast United States. This was partially attributed to the different emissivity assumptions that are used in each approach. Despite the possible bias in the GOES LST retrievals, the use of time tendencies eliminates the effect of these biases in the subsequent model assimilation procedures.

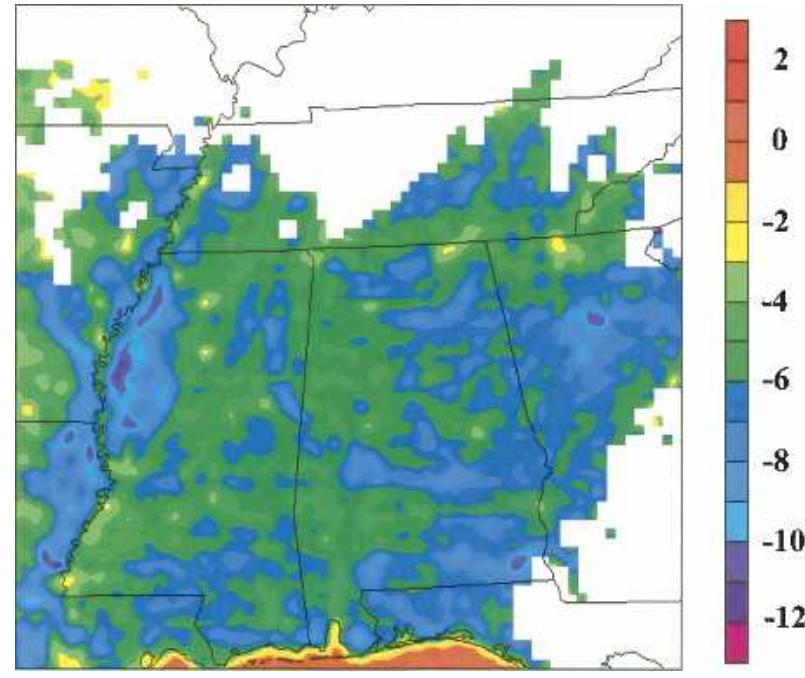

FIG. 4. Skin temperature tendencies $\left[{ }^{\circ} \mathrm{C}(3 \mathrm{~h})^{-1}\right]$ retrieved from GOES 19 May 2002 over the 3-h period ending at 2345 UTC (1845 CDT).

\section{Experiment design}

\section{a. Case study}

An initial trial of the technique to recover $C_{b s}$ using the early evening satellite skin temperature tendencies within the MM5 was conducted for a clear-sky case study over the southeastern United States on 19 May 2002. Figure 4 shows a depiction of the spatial variation in GOES-derived LST tendencies in late afternoon (1545-1845 CDT) over the Southeast in May 2002. A high degree of spatial correlation exists between the satellite-derived LST tendencies and USGS vegetation types as seen by comparing Figs. 2 and 4. As noted above, $C_{b}$ within a model grid cell is determined by a host of factors-soil type, soil moisture, biomass fraction, percent water in the biomass, and canopy exchange rates, just to name a few. The LST tendencies in Fig. 4 reflect some of these factors. Areas near the Mississippi River in western Tennessee where the satellite pixels cover water or swamplands have small cooling rates on order of $-5^{\circ} \mathrm{C}(3 \mathrm{~h})^{-1}$. In contrast, agricultural areas that are adjacent to but removed from the river, which have some bare ground, show larger cooling rates by a factor of 2. At this time of year crops such as cotton are not fully leafed out. Additionally, the heavily vegetated areas of the Smoky Mountains and Cumberland Plateau have smaller cooling rates.

The 500-hPa height field in Fig. 5a shows that the synoptic setting for this case is characterized by a highamplitude wave pattern with a trough centered in eastern Canada and the trailing ridge extending northward through the Plains States into central Canada. A 1037- 


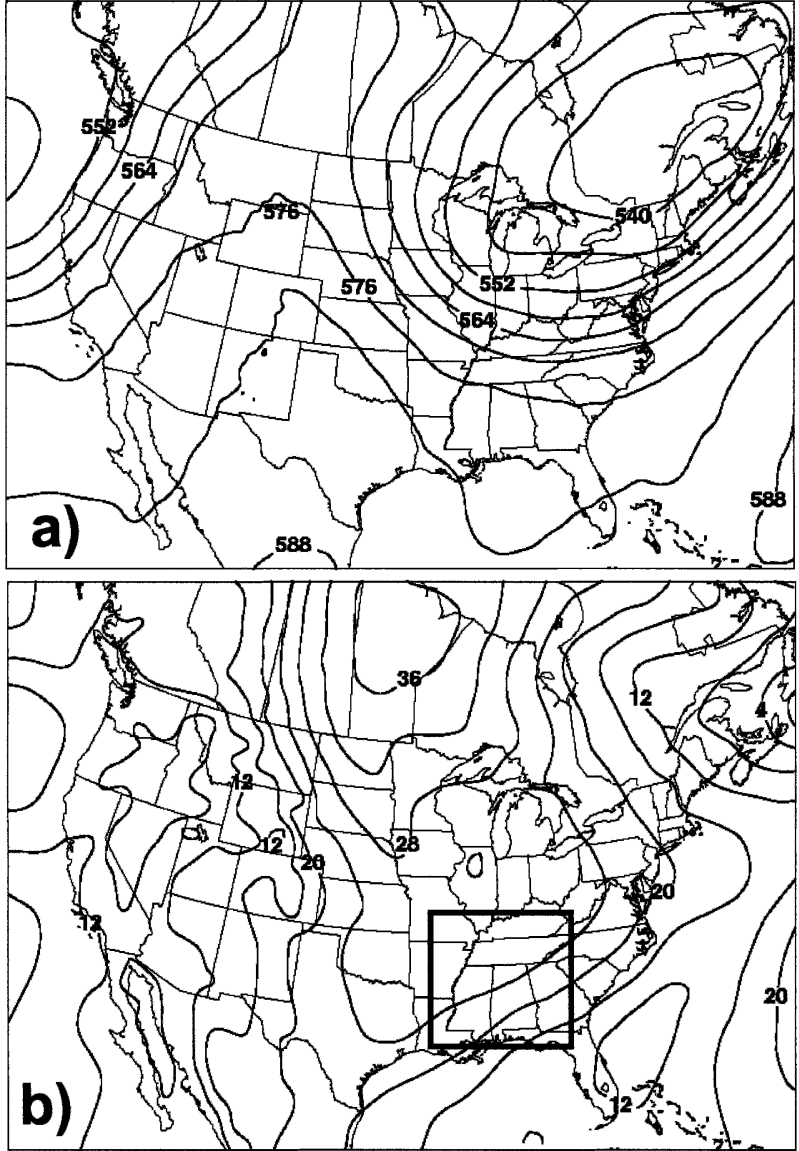

FIG. 5. Synoptic setting at 1200 UTC 19 May 2002: (a) 500-hPa heights (dam) and (b) sea level pressure (hPa). The box highlighted in (b) is the MM5 12-km domain.

$\mathrm{hPa}$ anticyclone (Fig. 5b) is located beneath the upperlevel ridge axis and extends southward into the central United States. A cold frontal boundary and associated cloud cover is situated along the east coast, and the western cloud edge extends northeastward from the central Florida Panhandle, through Georgia, into central North Carolina. The surface conditions over the model domain (not shown) indicate that winds behind the front are primarily from the north-northeast at less than $10 \mathrm{kt}\left(\sim 5 \mathrm{~m} \mathrm{~s}^{-1}\right)$. Temperatures range from near $12^{\circ} \mathrm{C}$ across the southern part of the domain to near $7^{\circ} \mathrm{C}$ in northern Tennessee.

By 0000 UTC, the frontal boundary and associated cloud field propagated eastward as the anticyclone continued to build southward. Surface air temperature rebounded approximately $15^{\circ}-17^{\circ} \mathrm{C}$ in response to the clear-sky conditions during the day despite the 10-15-kt northerly winds over the region. The pressure gradient weakened over night, allowing winds to become light and variable, and surface temperatures cooled nearly $15^{\circ} \mathrm{C}$ in the subsequent $12 \mathrm{~h}$.

\section{b. Model configuration}

The MM5 has a nested grid configuration consisting of a $36-\mathrm{km}$ coarse grid covering the contiguous lower 48 states and a $12-\mathrm{km}$ grid of dimension $73 \times 73$ points centered over north-central Alabama (Fig. 5b). The model is run in nonhydrostatic mode with 27 vertical levels and is initialized at 1200 UTC 19 May 2002. Initial conditions are obtained from the National Centers for Environmental Prediction (NCEP) Eta Data Assimilation System (EDAS) analysis (Rogers et al. 1996), available on the 40-km Advanced Weather Interactive Processing System (AWIPS) 212 grid. Fields are interpolated to the MM5 grid using the standard preprocessing software. Lateral boundary conditions for the coarse domain are obtained from 3-hourly forecasts of the NCEP Eta Model (Black 1994) on the AWIPS 212 grid. The vertical transport of momentum, heat, and moisture in the planetary boundary layer is calculated using a countergradient term as described by Hong and Pan (1996). Shortwave radiation interacts with atmosphere, clouds, precipitation, and the land surface as described by Dudhia (1989). The longwave atmospheric radiation is represented by the Rapid Radiative Transfer Model (RRTM) developed by Mlawer et al. (1997). The Kain-Fritsch cumulus scheme (Kain and Fritsch 1993) and simple ice microphysics (Dudhia 1989) are used for cloud and precipitation processes.

A total of three model runs, initialized with identical atmospheric analyses and configured with the same atmospheric parameterizations, were conducted and run out to $48 \mathrm{~h}$. A control run using the traditional fivelayer diffusion soil model described by Dudhia (1996) was produced using the default heat capacity parameters (Fig. 3) as specified by the 25-category USGS land use (Fig. 2). Two additional simulations complete the experiment design. The first additional run uses the satellite retrieval method to specify heat capacity. The only difference between it and the control is that the default heat capacity in the slab land surface scheme is replaced with the parameter recovered using the satellite data. This run is hereinafter referred to as the satellite heat capacity run. The third run employs the more detailed Oregon State University land surface scheme (LSM; Pan and Mahrt 1987) available within the MM5 package (Chen and Dudhia 2001). The OSU LSM is capable of predicting soil moisture and temperature in four layers from the surface down to $100 \mathrm{~cm}$. It contains predictive equations to explicitly predict moisture sources associated with evapotranspiration through vegetation and evaporation from bare soil. Surface fluxes used for input to the planetary boundary layer are determined from surface layer exchange coeffi- 
cients, radiative forcing, and precipitation. The vegetation indices and soil types are specified by the same USGS 25-category dataset that is used in the slab model. Therefore, the OSU LSM is initialized using the default heat capacity. However, it uses an energy balance method [Eq. (1)] so that heat capacity only enters through the soil model. Canopy transfer rates somewhat analogous to Eq. (7) are embedded within the scheme. Soil moisture is initialized from the EDAS analyses.

\section{Results}

\section{a. Retrieved heat capacity}

Simulated land surface temperature tendencies for $\left(d T_{G} / d t\right)_{m}$ in Eq. (14) are extracted from the control run during the 3-h period of 2045-2345 UTC 19 May (1545-1845 CDT). Satellite tendencies $\left(d T_{G} / d t\right)_{s}$ that are required to solve Eq. (15) are calculated for the same 3-h period as those extracted from the control run. Inspection of the simulated (Fig. 6) and satellite land surface temperature tendencies (Fig. 4) reveals several important differences. The land surface cooling rates during the 3-h period that are observed from the satellite are generally larger than those produced by the model. In fact, the model fails to produce cooling in any grid greater than $6^{\circ} \mathrm{C}(3 \mathrm{~h})^{-1}$. In addition, and perhaps most important, the satellite tendencies exhibit much more finescale variability. Features such as the agricultural areas or forested areas are not differentiated in the model.

Equation (15) is now solved for the satellite-retrieved heat capacity parameter using the default heat capacity (Fig. 2), along with the LST tendencies extracted from the control run (Fig. 6) and the corresponding values obtained from the satellite (Fig. 4). In areas where clouds prevent LST retrievals, the satellite-retrieved heat capacity is set to the default. The resulting satellite-derived heat capacity is displayed in Fig. 7. The results appear encouraging as the field appears to reflect structures associated with the underlying land use (Fig. 2). For example, the heavily vegetated areas in the Smoky Mountains and Cumberland Plateau extending down to north-central Alabama show up as having a high heat capacity, as might be expected as a result from the large amount of biomass with a high water content. The more sparsely vegetative surfaces representing more agricultural land in the Tennessee Valley between the Cumberland Plateau and Smoky Mountains yield a lower heat capacity. Similar results for the Mississippi River and adjacent agricultural areas are evident as well.

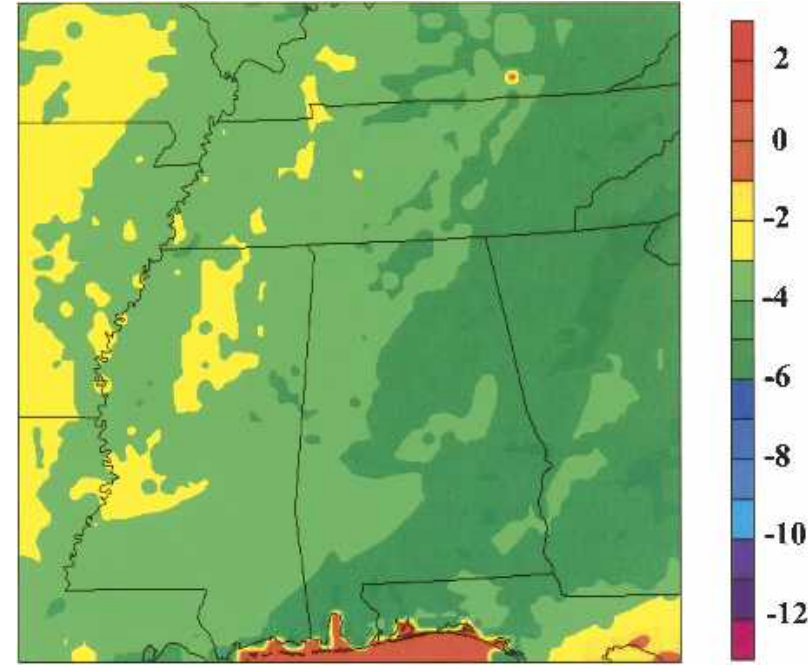

FIG. 6. Skin temperature tendencies $\left[{ }^{\circ} \mathrm{C}(3 \mathrm{~h})^{-1}\right.$ ] computed by MM5 using default land use heat capacity values 19 May 2002 ending at 2345 UTC (1845 CDT).

It should be noted that where the MM5 land/water mask indicates water, a satellite-derived heat capacity was not recovered. The low heat capacities over the Gulf of Mexico are default values, and they are not changed or used in the numerical experiments. It is interesting to note that the retrieval technique recovers large values of heat capacity near the land/water interface along the northern Gulf Coast. This is indicative of the fact that some of the grid cells that are categorized as land may actually be water. The retrieval technique could be exploited as a better technique to make these land/water designations especially along complex coast-

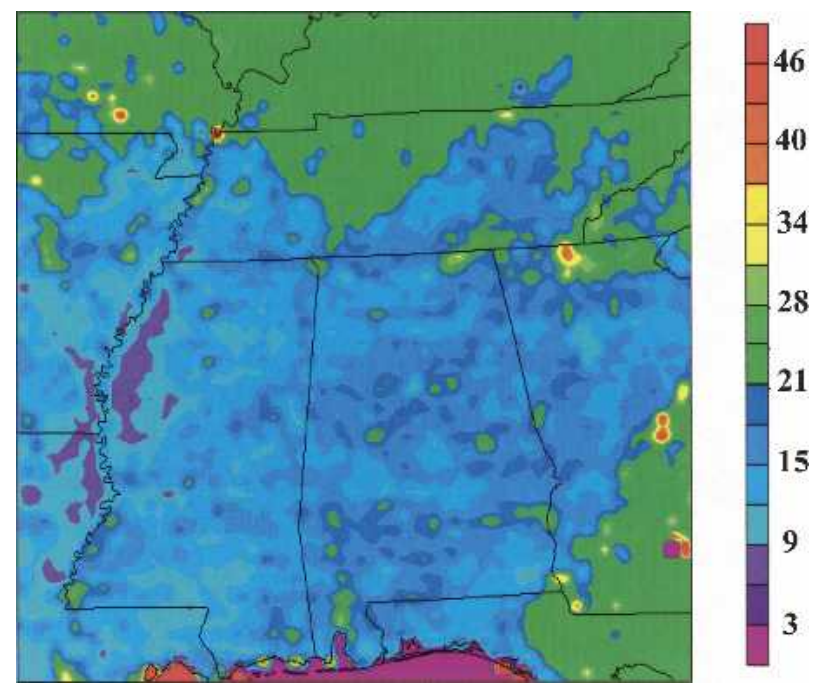

FIG. 7. Heat capacity $\left(\mathrm{KJ} \mathrm{m}^{-2} \mathrm{~K}^{-1}\right)$ retrieved from GOES tendencies using Eq. (14) in the text. 
lines or marshy areas within the mesoscale model systems.

\section{b. Impact on model performance}

The high degree of correlation between the retrieved heat capacities in Fig. 7 and land use type suggest they appear physical. However, the practical question is whether the use of these new heat capacities actually improves model performance. The selected case study is benign, meteorologically, in that there is no precipitation and relatively few clouds. As a result, radiative processes play a dominant role in the near-surface temperature tendencies. Analysis will focus on the ability of the models to replicate the observed diurnal cycle over the southeast from 1200 UTC May 19 to 1200 UTC 21 May 2002.

Hourly statistics of the bias and root-mean-square error (rmse) are calculated for the near-surface air temperature and dewpoint over the entire 12-km grid. All available National Weather Service (NWS) observing sites are used, providing an average of 90 observations per hour. Differences are calculated by interpolating model grid data to the observation location. Examination of the control run bias in Fig. 8 indicates relatively good performance during the daylight hours on both days. However, a warm bias of approximately $1.1^{\circ} \mathrm{C}$ develops on both nights. It is important to mention here that the MM5 is often found to have a warm bias at night. This is especially true when using the longwave radiation scheme of Dudhia (1989). In contrast, the RRTM has been noted to reduce the nighttime warm bias (Parsons and Dudhia 1997; Zamora et al. 2003) and is used in this study. Replacement of the default heat capacity by the satellite-retrieved heat capacity has little impact on the daytime bias in terms of both magnitude and trend. This is an important result given the relatively good performance of the control daytime simulation. The overall effect is a slight warming of $0.15^{\circ} \mathrm{C}$ on both days.

The largest impact of the satellite-derived heat capacities is a dramatic reduction of the nighttime warm bias. Both control and satellite heat capacity runs have a warm bias near $1^{\circ} \mathrm{C}$ at sunset on both days. However, the satellite heat capacity run bias approaches zero in the subsequent $5 \mathrm{~h}$ and remains near zero until sunrise. By 1300 UTC May 20 (25 h into the simulations), both the control and satellite heat capacity temperature biases are nearly identical again. The enhanced cooling found at night is consistent in that the satellite-derived heat capacities as seen in Fig. 5 are smaller than the default values. Thus, the smaller heat capacity would increase the cooling if the other dominant forcing such as downward longwave radiation remained constant.

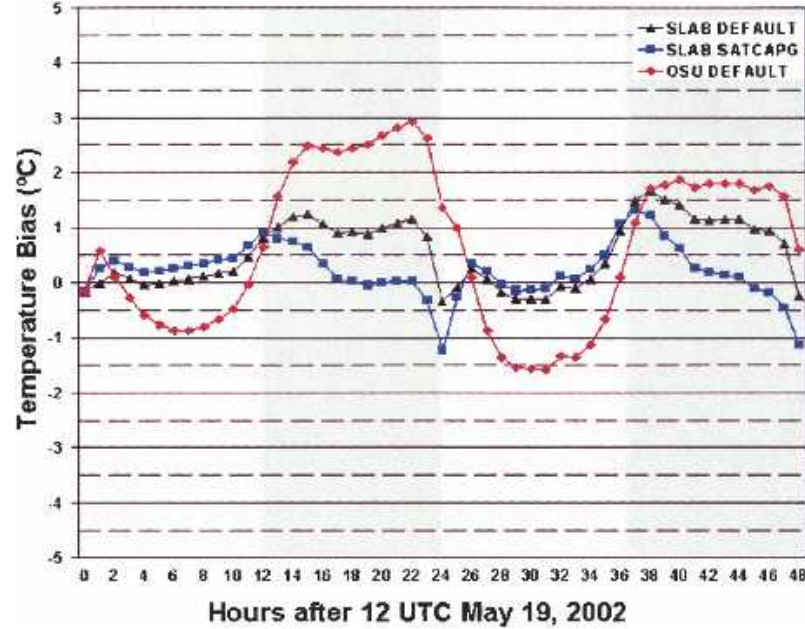

Fig. 8. Hourly 2-m air temperature $\left({ }^{\circ} \mathrm{C}\right)$ bias over the model domain for 48-h forecasts initialized at 1200 UTC 19 May 2002. MM5 default thermal inertia specified for the control run using the simple land surface scheme (SLAB DEFAULT) and Oregon State University land surface scheme (OSU DEFAULT). The simple thermal diffusion land surface scheme was initialized with the GOES-inferred heat capacity (SLAB SATCAPG). Shading indicates overnight hours from 0000 to 1200 UTC.

Other forcing mechanisms such as turbulent heat flux and outgoing longwave are not necessarily constant.

The OSU LSM run has the largest temperature bias of the three model configurations used in this study. The bias is cold during daylight hours on both days and is largest during midday with values close to $1^{\circ} \mathrm{C}$ in day 1 and $1.6^{\circ} \mathrm{C}$ on day 2 . The nights are characterized by a significant warm bias of $2.5^{\circ} \mathrm{C}$ on the first night with a maximum just before sunrise of $2.9^{\circ} \mathrm{C}$. The bias is not as large on the second night but still approaches $1.8^{\circ} \mathrm{C}$ for the duration.

A diurnal trend in the magnitude of the rmse similar to the bias is found in all simulations, and the largest values occur during the nighttime hours (Fig. 9). The satellite-retrieved heat capacity has little impact during the day but provides a slight improvement during the night of about $0.2^{\circ} \mathrm{C}$, or $10 \%$ of the total error. The OSU LSM has the largest rmse of the runs throughout the simulation period with the largest values near $3.0^{\circ} \mathrm{C}$ on both nights.

The dewpoint statistics shown in Fig. 10 indicates that all three simulations have a dry bias and exhibit similar trends. As was the case with temperature, use of the satellite-derived heat capacity has little impact on the dewpoint bias during the daylight hours. There is a $20 \%$ increase of the dry bias that is evident on both nights. The OSU LSM dry bias is better than both the control and satellite heat capacity runs on both days by approximately $20 \%$ but it is considerably worse by a 


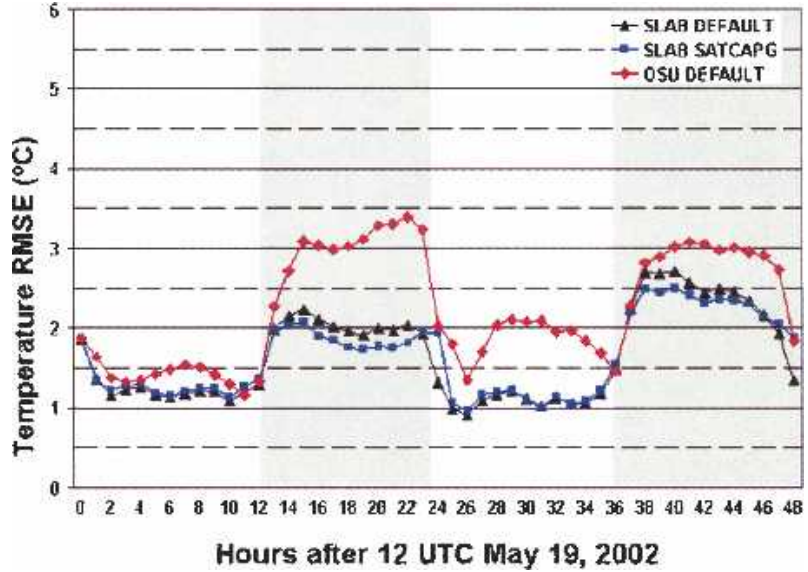

FIG. 9. Hourly $2-\mathrm{m}$ air temperature $\left({ }^{\circ} \mathrm{C}\right)$ rmse over the model domain for 48-h forecasts initialized at 1200 UTC 19 May 2002. MM5 default thermal inertia specified for the control run using the simple land surface scheme (SLAB DEFAULT) and Oregon State University land surface scheme (OSU DEFAULT). The simple thermal diffusion land surface scheme was initialized with the GOES-inferred heat capacity (SLAB SATCAPG). Shading indicates overnight hours from 0000 to 1200 UTC.

factor of 2 during the nights. The same trends are evident in the dewpoint rmse (not shown).

It is clear from the verification statistics that the simple slab formulation using the satellite-retrieved heat capacity produced the most realistic surface tem-

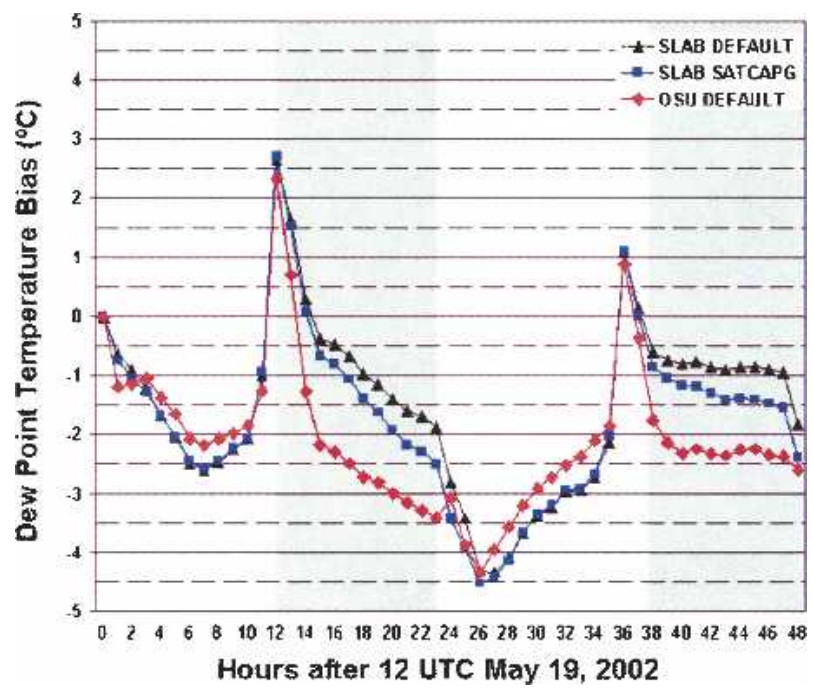

FIG. 10. Hourly 2-m dewpoint temperature bias $\left({ }^{\circ} \mathrm{C}\right)$ over the model domain for 48-h forecasts initialized at 1200 UTC 19 May 2002. MM5 default thermal inertia specified for the control run using the simple land surface scheme (SLAB DEFAULT) and Oregon State University land surface scheme (OSU DEFAULT). The simple thermal diffusion land surface scheme was initialized with the GOES-inferred heat capacity (SLAB SATCAPG). Shading indicates overnight hours from 0000 to 1200 UTC. perature forecast for this specific event. Results for the dewpoint were not as good as the control run during the evenings, but differed by less than $20 \%$. One could argue that the relatively poor performance of the OSU LSM in this case should not be regarded as the norm. The OSU scheme is fundamentally sound in terms of physical parameterizations, and numerous studies have reported positive results. The performance of the scheme is obviously sensitive to the specification of surface characteristics such as vegetation fraction, rooting depth, soil types, and soil moisture. No attempt was made in this study to develop a modified soil moisture field using antecedent precipitation analyses. The soil moisture was initialized in typical fashion using the fields in the EDAS analyses; although, perhaps coarse, it does contain an antecedent precipitation analysis. Given that the focus of this paper is on the nighttime energy budget, it is not obviously clear what impact adjusting the OSU soil moisture would have on the results obtained there from. However, it is noted that a heavy and widespread precipitation event occurred 2 days before this case study. Precipitation in excess of 0.5 in. $(\sim 1.25 \mathrm{~cm})$ fell in a 24-h period ending at 1200 UTC 18 May over the majority of the model domain. If other offline methods were used to modify EDAS soil moisture analysis for this event, one would assume an overall moistening and a reduction of the dry bias in the OSU LSM run. However, it would also be expected to reduce sensible heat fluxes and cause a worsening of the cold bias found during the daylight hours under conditions of strong solar forcing.

Verification statistics that are presented above are averaged over the entire model domain, while the satellite heat capacity was only retrieved where skies were clear at 1545 and 1745 CDT 19 May. Therefore, a percentage of the observation-model temperature pairs used to calculate the bulk verification statistics are located within areas where the satellite heat capacity could not be retrieved and the values were set to the default. The spatial distribution of the 2-m temperature difference between the control run and the satellite heat capacity run is used to illustrate the impact of using the satellite-retrieved heat capacities. Figure 11 shows the difference field in the early morning hours before sunrise at the 22-h forecast that is valid at 1000 UTC 20 May when the domain biases were $+1.0^{\circ}$ and $0^{\circ} \mathrm{C}$ for the control and satellite heat capacity runs, respectively. The control 2-m temperature field is found to be warmer that the satellite heat capacity run and the largest difference in excess of $1.8^{\circ} \mathrm{C}$ is found over the agricultural regions along the Mississippi River. The response is consistent with the fact that the satellite- 


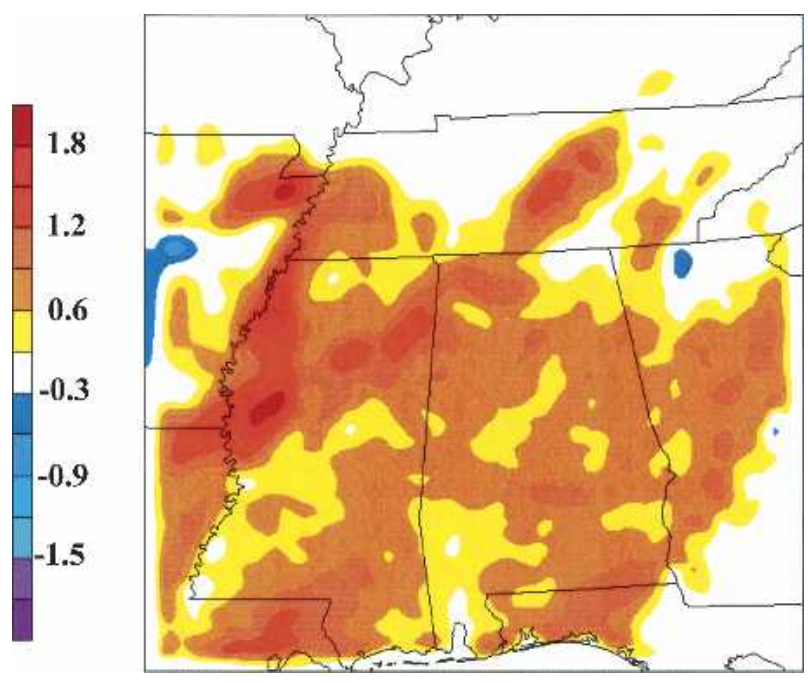

FIG. 11. The 2-m temperature difference (control minus satellite capacity run; ${ }^{\circ} \mathrm{C}$ ) over the model domain for the 22 -h forecast valid at 1000 UTC 20 May 2002.

recovered heat capacity values are typically lower than the default values (cf. Figs. 3 and 7).

In summary, the results from this first attempt look very promising in that model performance at night is significantly improved. However, the results obtained from the OSU scheme should be viewed with some caution. As stated above, it is recognized that the scheme is sensitive to the initial specification of soil moisture and new high-resolution offline methods for initialization are becoming available to the modeling community (see Chen et al. 2004 or Xiu and Pleim 2001). However, the majority of MM5 users do not currently have access to offline methods of soil moisture initialization and typically use fields obtained from analysis systems, such as EDAS.

\section{Summary and conclusions}

The bulk heat capacity is a difficult-to-define quantity for a model grid that is several kilometers in scale. Its value depends on both the gross heat capacity and exchange rates within the grid. In actual practice these heat capacities and exchange rates are the result of a combination of surfaces from soils, to plant canopies, to standing water, or to man-made structures. Investigators such as Carlson et al. (1981) recognized from an observational perspective that model parameters such as soil heat capacity and soil diffusivity lost their meanings in highly heterogeneous settings. They defined a parameter, thermal inertia $(\chi)$, as simply being a parameter that controls the change in surface temperature for a given forcing. Individual components such as heat capacity or thermal conductivity could be extracted, if needed, if one or the other were specified. In the model of Carlson et al. (1981) changes in temperature could be related to $\chi$ after the fact through the definition of $\chi$, but $\chi$ did not appear as an explicit parameter in the equations.

In this investigation we follow Wetzel and Chang (1988), and others listed in section 2 above, in utilizing the bulk heat capacity $C_{b}$ or its inverse $\left(C_{T}\right)$, which does appear as an explicit parameter in the model. In utilizing $C_{b}$ as separate parameter it might be argued that the soil heat flux term $G$ not be used in the surface temperature equation because it could be wrapped within $C_{b}$. However, in keeping with the traditional model structure we have retained this form.

The first results of a retrieval of $C_{b}$ based on observations from satellites appear promising. It is recognized that a limiting factor of the technique is the inability to recover heat capacity under cloudy conditions. However, this negative impact can be mitigated by applying the technique sequentially on a sequential daily basis. The transient nature of cloud patterns over time will eventually allow the heat capacity to be recovered over the entire model domain. Such a configuration would allow daily and seasonal changes in the recovered heat capacity to be evaluated. In addition, the technique could also be configured to recover surface moisture in the morning (McN94) and heat capacity in the evening.

It should be recognized, however, that $C_{b}$ is a model heuristic and does not have the physical meaning of a true substance heat capacity. There are additional issues with the sensitivity of the model system to $C_{b}$. Last, there are issues about how well the boundary layer model performs in the nocturnal boundary layer where we are making certain assumptions about the robustness of the model in making the $C_{b}$ retrievals. There are parameter spaces in terms of wind and roughness where the nocturnal boundary layer makes abrupt transitions between a decoupled state and a turbulently connected state (McNider et al. 1995). Thus, retrievals of $C_{b}$ may be limited to certain wind regimes. These issues will be dealt with in a separate paper (Part II).

Acknowledgments. This work has been partially supported by the following grants: U.S. EPA Star Grant R-826770-01-0, NASA GEWEX Grant NCC8-200, Southern Oxidant Study, U.S. EPA Cooperative Agreement R-82897701-0, NSF-ATM-0417774, EPANOAA memorandum DW13921548, and Houston Advanced Research Center Contract HARC-H232003C2. Note the results in this study do not necessarily reflect policy or science positions by the funding agencies. 


\section{REFERENCES}

Argentini, S., P. J. Wetzel, and V. M. Karyampudi, 1992: Testing a detailed biophysical parameterization for land-air exchange in a high-resolution boundary-layer model. J. Appl. Meteor., 31, 142-156.

Bhumralkar, C. M., 1975: Numerical experiments on the computations of ground temperature in general circulation model. $J$. Appl. Meteor., 14, 1246-1258.

Black, T. L., 1994: The new NMC mesoscale Eta Model: Description and forecast examples. Wea. Forecasting, 9, 265-278.

Blackadar, A. K., 1979: High resolution models of the planetary boundary layer. Adv. Environ. Sci. Eng., 1, 50-85.

Boone, A., V. Masson, T. Meyers, and J. Noilhan, 2000: The influence of the inclusion of soil freezing on simulations by a soil-vegetation-atmosphere transfer scheme. J. Appl. Meteor., 39, 1544-1569.

Carlson, T. N., 1986: Regional scale estimates of surface moisture availability and thermal inertia using remote thermal measurements. Remote Sens. Rev., 1, 197-246.

_, J. K. Dodd, S. G. Benjamin, and J. N. Cooper, 1981: Satellite estimation of the surface energy balance, moisture availability and thermal inertia. J. Appl. Meteor., 20, 67-87.

Chen, F., and J. Dudhia, 2001: Coupling an advanced land surface-hydrology model with the Penn State-NCAR MM5 modeling system. Part II: Preliminary model validation. Mon. Wea. Rev., 129, 587-604.

- , K. W. Manning, D. N. Yates, M. A. Lemone, S. B. Trier, R. Cuenea, and D. Niyogi, 2004: Development of a high resolution land data assimilation system (HRLDAS). Preprints, 16th Conf. on Numerical Weather Prediction, Seattle, WA, Amer. Meteor. Soc., CD-ROM, 22.3.

Diak, G. R., and C. Gautier, 1983: Improvements to a simple physical model for estimating insolation from GOES data. $J$. Climate Appl. Meteor., 22, 505-508.

—_, and M. S. Whipple, 1995: Note on estimating surface sensible heat fluxes using surface temperatures measured from a geostationary satellite during FIFE 1989. J. Geophys. Res., 100, $25453-25461$.

Dudhia, J., 1989: Numerical study of convection observed during the Winter Monsoon Experiment using a mesoscale twodimensional model. J. Atmos. Sci., 46, 3077-3107.

__ 1996: A multi-layer soil temperature model for MM5. Preprints, Sixth PSU/NCAR Mesoscale Models User's Workshop, Boulder, CO, NCAR, 49-50.

Garand, L., and Coauthors, 2001: Radiance and Jacobian intercomparison of radiative transfer models applied to HIRS and AMSU channels. J. Geophys. Res., 106, 24 017-24 031.

Gautier, C., G. R. Diak, and S. Mass, 1980: A simple physical model for estimating incident solar radiation at the surface from GOES satellite data. J. Appl. Meteor., 19, 1005-1012.

Giard, D., and E. Bazile, 2000: Implementation of a new assimilation scheme for soil and surface variables in a global NWP model. Mon. Wea. Rev., 128, 997-1015.

Grell, G. A., J. Dudhia, and D. R. Stauffer, 1994: The Penn State/ NCAR Mesoscale Model (MM5). NCAR Tech. Note NCAR/ TN-398+STR, 138 pp.

Guillory, A. R., G. J. Jedlovec, and H. E. Fuelberg, 1993: A technique for deriving column-integrated water content using VAS split window data. J. Appl. Meteor., 32, 1226-1241.

Haines, S. L., G. J. Jedlovec, and R. J. Suggs, 2004: The GOES product generation system. NASA Marshall Space Flight Center Tech. Memo., NASA/TM-2004-213286, 64 pp.
Hong, S., and H. Pan, 1996: Nonlocal boundary layer vertical diffusion in a Medium-Range Forecast Model. Mon. Wea. Rev., 124, 2322-2339.

Jacquemin, B., and J. Noilhan, 1990: Sensitivity study and validation of a land surface parameterization using the HapexMobilhy Data Set. Bound.-Layer Meteor., 52, 93-134.

Jedlovec, G. J., 1987: Determination of atmospheric moisture structure from high-resolution MAMS radiance data. Ph.D. dissertation, University of Wisconsin-Madison, $187 \mathrm{pp}$.

-, and K. Laws, 2003: GOES cloud detection at the Global Hydrology and Climate Center. Preprints, 12th Conf. on Satellite Meteorology and Oceanography, Long Beach, CA, Amer. Meteor. Soc., CD-ROM, P1.21.

Jones, A. S., I. C. Guch, and T. H. Vonder Haar, 1998a: Data assimilation of satellite-derived heating rates as proxy surface wetness data into a regional atmospheric mesoscale model. Part I: Methodology. Mon. Wea. Rev., 126, 634-645.

$\longrightarrow, \ldots$, and $—$ 1998b: Data assimilation of satellite-derived heating rates as proxy surface wetness data into a regional atmospheric mesoscale model. Part II: A case study. Mon. Wea. Rev., 126, 646-667.

Kain, J. S., and J. M. Fritsch, 1993: Convective parameterization for mesoscale models: The Kain-Fritsch scheme. The Representation of Cumulus Convection in Numerical Models, Meteor. Monogr., No. 46, Amer. Meteor. Soc., 156-170.

Koster, R. D., and M. J. Suarez, 1992: A comparative analysis of two land surface heterogeneity representations. J. Climate, 5, 1379-1390.

Lapenta, W. M., R. Suggs, G. J. Jedlovec, and R. T. McNider, 1999: Impact of assimilating GOES-derived land surface variables into the PSU/NCAR MM5. Preprints, Workshop on Land-Surface Modeling and Applications to Mesoscale Models, Boulder CO, NCAR, 65-68.

Mahfouf, J.-F., 1991: Analysis of soil moisture from near surface parameters: A feasibility study. J. Appl. Meteor., 30, 15341547.

— - A. O. Manzi, J. Noilhan, H. Giordani, and M. DéQué, 1995: The land surface ISBA scheme within the Météo-France climate model ARPEGE. Part I: Implementation and preliminary results. J. Climate, 8, 2039-2057.

Mahrer, Y., and R. A. Pielke, 1976: A numerical study of flow over irregular terrain. Contrib. Atmos. Phys., 50, 98-113.

Manzi, A. O., and S. Planton, 1994: Implementation of the ISBA parameterization scheme for land surface processes in a GCM. J. Hydrol., 155, 355-389.

McCumber, M., and R. Pielke, 1981: Simulation of the effects of surface fluxes of heat and moisture in a mesoscale model. $J$. Geophys. Res., 86C, 9929-9938.

McMillin, L. M., and H. E. Fleming, 1976: Atmospheric transmittance of an absorbing gas: A computationally fast and accurate transmittance model for absorbing gases with constant mixing ratios in inhomogeneous atmospheres. Appl. Opt., 15, 358-363.

McNider, R. T., and R. A. Pielke, 1981: Diurnal boundary layer development over sloping terrain. J. Atmos. Sci., 38, 21982212.

—, A. J. Song, D. M. Casey, P. J. Wetzel, W. L. Crosson, and R. M. Rabin, 1994: Toward a dynamic-thermodynamic assimilation of satellite surface temperature in numerical atmospheric models. Mon. Wea. Rev., 122, 2784-2803.

_ D. E. England, M. J. Friedman, and X. Shi, 1995: Predictability of the stable atmospheric boundary layer. J. Atmos. Sci., 52, 1602-1614. 
Menzel, W. P., and J. F. W. Purdom, 1994: Introducing GOES-I: The first of a new generation of geostationary operational environmental satellites. Bull. Amer. Meteor. Soc., 75, 757781.

Noilhan, J., and S. Planton, 1989: A simple parameterization for land surfaces in meteorological models. Mon. Wea. Rev., 117, 536-549.

Norman, J. M., W. P. Kustas, and K. S. Humes, 1995: A twosource approach for estimating soil and vegetative fluxes from observations of directional radiometric surface temperature. Agric. For. Meteor., 77, 263-293.

Pan, H.-L., and L. Mahrt, 1987: Interaction between soil hydrology and boundary-layer development. Bound.-Layer Meteor., 38, 185-202.

Parsons, D. B., and J. Dudhia, 1997: Testing of a data assimilation system in support of the goals of the Atmospheric Radiation Measurement Program. Mon. Wea. Rev., 125, 2353-2381.

Peters-Lidard, C. D., E. Blackburn, X. Liang, and E. F. Wood, 1998: The effect of soil thermal conductivity parameterization of surface energy fluxes and temperatures. J. Atmos. Sci., $\mathbf{5 5}, 1209-1224$.

Physick, W., 1976: A numerical model of the sea-breeze phenomena over a lake or gulf. J. Atmos. Sci., 33, 2107-2135.

Pleim, J. E., and A. Xiu, 1995: Development and testing of a surface flux and planetary boundary layer model for application in mesoscale models. J. Appl. Meteor., 34, 16-32.

Price, J. C., 1982: On the use of satellite data to infer surface fluxes at meteorological scales. J. Appl. Meteor., 21, 11111122.

Rao, C. R. N., J. Chen, J. T. Sullivan, and N. Zhang, 1999: Post launch calibration of meteorological satellite sensors. $A d v$. Space Res., 23, 1357-1365.

Rogers, E., D. Parrish, Y. Lin, and G. DiMego, 1996: The NCEP Eta data assimilation system: Tests with regional 3-D variational analysis and cycling. Preprints, 11th Conf. on Numeri- cal Weather Prediction, Norfolk, VA, Amer. Meteor. Soc., 105-106.

Smirnova, T. G., J. M. Brown, and S. G. Benjamin, 1997: Performance of different soil model configurations in simulating ground surface temperature and surface fluxes. Mon. Wea. Rev., 125, 1870-1884.

Suggs, R. J., G. J. Jedlovec, and A. R. Guillory, 1998: Retrieval of geophysical parameters from GOES: Evaluation of a split window retrieval technique. J. Appl. Meteor., 37, 1205-1227.

— , S. L. Haines, G. J. Jedlovec, W. Lapenta, and D. Moss, 2003: Land surface temperature retrievals from GOES-8 using emissivities from MODIS. Preprints, 12th Conf. on Satellite Meteorology and Oceanography, Long Beach, CA, Amer. Meteor. Soc., CD-ROM, P4.19.

Viterbo, P., A. Beljaars, J. Mahfouf, and J. Teixeira, 1999: The representation of soil moisture freezing and its impact on the stable boundary layer. Quart. J. Roy. Meteor. Soc., 125, 24012426.

Wan, Z., and J. Dozier, 1996: A generalized split-window algorithm for retrieving land-surface temperature from space. IEEE Trans. Geosci. Remote Sens., 34, 892-905.

Wetzel, P. J., and J.-T. Chang, 1988: Evapotranspiration from nonuniform surfaces: A first approach for short-term numerical weather prediction. Mon. Wea. Rev., 116, 600-621.

_ D. D. Atlas, and T. H. Woodward, 1984: Determining soil moisture from geosynchronous satellite infared data: A feasibility study. J. Climate Appl. Meteor., 23, 375-391.

Xiu, A., and J. E. Pleim, 2001: Development of a land surface model. Part I: Application in a mesoscale meteorology model. J. Appl. Meteor., 40, 192-209.

Zamora, R. J., and Coauthors, 2003: Comparing MM5 radiative fluxes with observations gathered during the 1995 and 1999 Nashville Southern Oxidants Studies. J. Geophys. Res., 108, 4050, doi:10.1029/2002JD002122. 